This item was submitted to Loughborough's Research Repository by the author.

Items in Figshare are protected by copyright, with all rights reserved, unless otherwise indicated.

\title{
The determinants of technology diffusion: evidence from the UK financial
} sector

PLEASE CITE THE PUBLISHED VERSION

PUBLISHER

(c) Loughborough University

LICENCE

CC BY-NC-ND 4.0

REPOSITORY RECORD

Gourlay, Adrian R., and Eric J. Pentecost. 2019. "The Determinants of Technology Diffusion: Evidence from the UK Financial Sector”. figshare. https://hdl.handle.net/2134/731. 
This item was submitted to Loughborough's Institutional Repository by the author and is made available under the following Creative Commons Licence conditions.

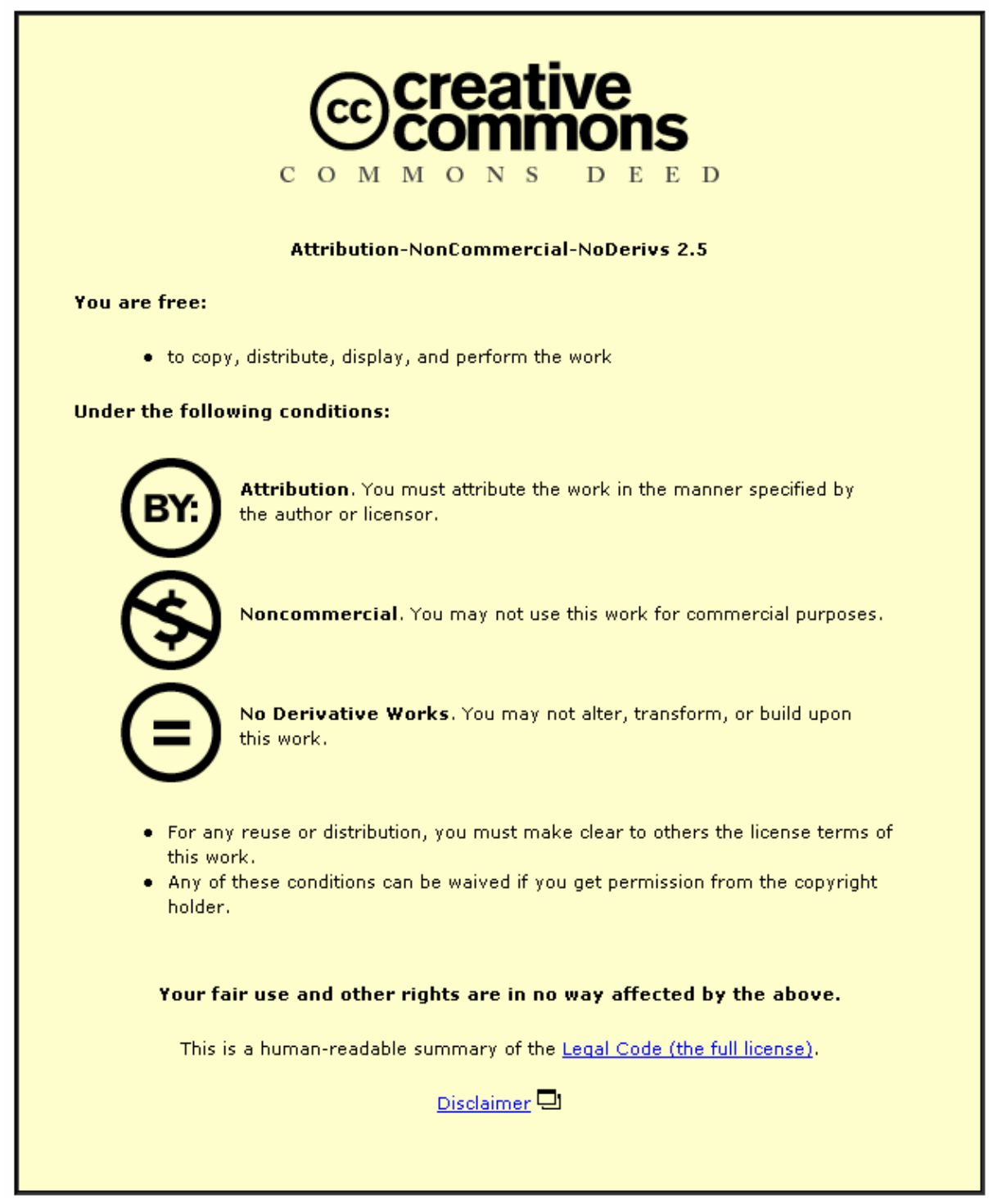

For the full text of this licence, please go to: http://creativecommons.org/licenses/by-nc-nd/2.5/ 
Department of Economics

Economic Research Paper No. 00/9

\section{The Determinants of Technology \\ Diffusion: Evidence from the UK}

\section{Financial Sector}

Adrian R. Gourlay and Eric J. Pentecost

August 2000

ㄴoughborough University 
Centre for International, Financial and Economics Research Department of Economics

Loughborough University

Loughborough

Leics., LE11 3TU

UK

Tel: $+44(0) 1509222734$

Fax: + 44 (0) 1509223910

Email: E.J.Pentecost@lboro.ac.uk

$\begin{array}{ll}\text { Director : } & \text { Dr Eric J Pentecost } \\ \text { Deputy Director : } & \text { Professor C J Green }\end{array}$

Associate Directors:

Professor Kenneth J Button,George Mason University, USA

Professor Peter Dawkins, University of Melbourne, Australia

Professor Robert A Driskill, Vanderbilt University, USA

Professor James Gaisford, University of Calgary, Canada

Professor Andre van Poeck, University of Antwerp, Belgium

Professor Amine Tarazi, University of Limoges, France 


\title{
The Determinants of Technology Diffusion: Evidence from the UK Financial Sector
}

\author{
by \\ ADRIAN GOURLAY $Y^{\dagger}$ AND ERIC PENTECOST \\ Department of Economics, Loughborough University, LE11 3TU, England
}

This paper investigates the role of firm and industry-specific factors in the diffusion of automated teller machines (ATMs) in the UK financial sector. A duration model of technology adoption is employed in the empirical modelling and is applied to an annual panel of adoption histories over the period 1972 - 1997. The main factors affecting the diffusion of new technology are found to be endogenous learning, cumulative learning-by-doing effects, firm size, growth and profitability, and price expectations. There is, however, little evidence to support the role of stock effects in the diffusion process. The results are found to be robust across a number of specifications of the baseline hazard function.

Key Words: innovation, diffusion, duration models, financial sector

JEL Classification: G21, O31

Corresponding author. 


\section{INTRODUCTION}

Research into the inter-firm diffusion of new technology has paid relatively little attention to the determinants of innovation diffusion in the financial sector. This is in contrast to the growing theoretical and empirical literature examining diffusion in the industrial sector. ${ }^{1}$ Arguably, this paucity in the literature needs to be addressed given the rapid product and process innovation experienced by the United Kingdom (UK) financial sector over the last two decades (Bank of England, 1986; Pawley, 1993; Llewellyn, 1992, 1997). The payments system, in particular, has presented an abundance of opportunities for the wider use of information technology (IT). This is largely due to its main functions being focussed on the availability, storage, retrieval and transmission of information. One such technology is the automated teller machine (ATM) which has been widely adopted by retail banks and building societies since their commercialisation in 1972. An ATM is an automated cash dispenser (with additional transaction services) which allows holders of an appropriate cash, debit or credit card to access their retail deposit accounts in order to withdraw and deposit cash. Thus, the ATM can be interpreted as both a process and a product innovation

The reasons why firms do not instantaneously adopt new technology immediately after its commercialisation (i.e. diffusion is a time-intensive process) can be traced to different theories of innovation diffusion advocated in the literature. According to early epidemic theories of inter-firm diffusion (Griliches, 1957; Mansfield, 1968), diffusion is a disequilbrium process resulting from information asymmetries between potential users (Lesson and Metcalfe, 1994; Baptista, 2000).

In contrast to epidemic models, contemporary approaches to technology diffusion are characterised by the dismissal of information spreading as the key explanatory variable of innovation diffusion. Rather, models (in general) assume that firms behave optimally (i.e., are profit maximisers) and that information pertaining to the technological and economic characteristics of the innovation is perfect. Within this equilibrium approach there are three categories of models that have been developed in the literature (Karshenas and Stoneman, 1995; Sarkar, 1998): the rank or probit; stock or game theoretic, and order effects.

In rank or probit models (Davies, 1979; Ireland and Stoneman, 1986) potential adopters of a technology have different inherent characteristics and consequently obtain different gross returns from its use. These different characteristics generate different preferred adoption dates.

\footnotetext{
${ }^{1}$ See Sarkar (1998) and Geroski (2000) for recent reviews of the relevant literature.
} 
Hannan and McDowell (1984, 1987) and Sinha and Chandrashekaran (1992) find strong support for the existence of rank effects in the diffusion of ATMs in the US banking sector. Firm size and variables capturing the proportion of demand deposits to total deposits are found to have a positive effect on the (conditional) probability of adoption. Institutional variables are also found to have a significant effect on adoption. Hannan and McDowell (1987), however, reject the existence of epidemic effects. Results obtained by Ingham and Thompson (1993) for the diffusion of ATMs in the UK building society sector confirm the importance of rank effects. Advertising expenditure and labour costs are found to have a positive effect on the probability of adoption, although variables capturing the mix of retail deposits are found to be insignificant.

The essence of the stock effects models (Reinganum, 1981a, 1981b, 1989; Quirmbach, 1986) is that benefits to the marginal adopter from acquisition decreases as the number of previous adopter's increases. As firms acquire new technology, their production costs fall. This leads to changes in the output of firms and the industry, thereby affecting industry prices and the profitability of further adoption. Order effect models are similar to the rank effect models in that the gross returns to a firm adopting new technology depends upon its position in the order of adoption, with higher order adopting firms achieving a greater return than low-adopters. ${ }^{2}$ As noted by Baptista (2000), however, the stock and order effects models will have opposite effects on the probability of adoption. The stock effects focuses on the equilibrium number of adopters and the subsequent lower profitability of adoption, whilst the order effects focus on the anticipation of subsequent adoptions. Hence, the stock effect has a negative effect on the probability of adoption, and the order effects a positive effect.

Hannan and McDowell (1987) find a significant and positive relationship between the number of previous adopters at the state level (as a proxy for the stock effect) and the probability of ATM adoption in the US banking sector. To date, however, empirical testing of stock and order effects has been predominately on the diffusion of technologies in the industrial sector (see Karshenas and Stoneman, 1993; Colombo and Mosconi, 1995; Baptista, 2000).

There are two aims to this present paper. The first is to examine the determinants of ATM diffusion in the UK financial sector. A general duration model of diffusion is built, which allows the incorporation of rank, stock and order effects. Empirical testing of the

\footnotetext{
${ }^{2}$ This can be justified on two grounds. First, pre-emption and first-mover advantages (Fudenberg and Tirole, 1985). Second, advantages relating to the acquisition of prime geographic sites or limited pools of skilled labour (Ireland and Stoneman, 1985).
} 
model is performed by employing a panel of adoption histories for a stock of UK financial institutions from 1972 to 1997 . The second objective is to test the robustness of the results across a range of different assumptions relating to the underlying hazard rate of adoption.

\section{A MODEL OF TECHNOLOGY ADOPTION}

As illustrated by Karshenas and Stoneman (1993, 1995), Colombo and Mosconi (1995), and Baptista (2000) it is possible to subsume alternative theories of diffusion into one encompassing model. The specification of an encompassing model then enables one to test empirically which (if any) of the epidemic, rank, stock, order effects play a significant role in the diffusion process. Throughout this paper, ATM technology is modelled as being embodied in a specific capital good supplied by a capital producing industry.

The model assumes that a new technology can be adopted by financial institution $i$ in industry $j$ by purchasing one unit of the technology at price $P_{t}$ at time $t$. Furthermore, $g_{i j \tau}$ is defined as the (gross) profit obtained by a firm in period $\tau$ from the use of the ATM. Rank, stock and order effects determine per-period profits. ${ }^{3}$ Specifically, the arguments of $g_{i j}($. are assumed to be a vector of characteristics of the firm $C_{i}$ (reflecting the rank effects), the number of firms already using the new technology at time $t, K_{i t}$, reflecting the stock effects and the number of previous adopters at the date of adoption, $K_{i \tau}$, reflecting the order effects. Although $K_{i \tau}=K_{i t}$ by definition, both terms are initially entered as separate arguments into the determinants of $g_{i j}($.$) to keep the stock and order effects conceptually separate. Firms$ are assumed to behave with perfect foresight conjectures.

In both the stock and order effects, the return in each period of use is dependent upon the number of other adopters at that date, whilst for the rank effects the returns in each period are independent of other users. For the $i$ th institution adopting an ATM in time $t$, its per period (or annual) benefits in time $\tau$ from adoption at time $t, \tau \geq t$, is ${ }^{4}$

$$
g_{i j}(\tau)=g\left[C_{i}, K_{i \tau}, K_{i t}\right] \tau \geq t, g_{2} \leq 0, g_{3} \leq 0
$$

\footnotetext{
${ }^{3}$ The theoretical model and the subsequent empirical model explicitly ignore supply side influences in the diffusion process. This is arguably not a restrictive restriction for the case of ATM technology given the extent of imported technology. See Kirkman (1987) and Austin (1992).

${ }^{4}$ The partial effects of $C_{i}$ in (1) cannot be determined a priori and ultimately depends on which institutionspecific characteristics are deemed to affect the optimal time of adoption.
} 
In the empirical implementation of the model it is assumed that all institutions belong to the same industry so that $j=1$.

The net present value of the increase in gross profits arising from adopting at time $t$ with discount factor $r$, in continuous time can be written as

$$
\mathrm{Y}_{i t}=-P_{t}+\int_{t}^{\infty} g(.) \cdot \exp [-r(\tau-t)] d t
$$

The institution is then assumed to choose an optimal time of adoption (taken from the commercialisation of the ATM for which $t=0), t^{*}$, that is determined by two necessary and sufficient conditions. The first is that adoption yields positive profits, i.e., $Y_{i t} \geq 0$. The second condition is referred to as the arbitrage condition (Karshenas and Stoneman, 1993, 1995). The arbitrage condition requires that for adoption it must not be more profitable to wait beyond $t^{*}$, i.e., the net benefit from adoption must not be increasing over time. This can be represented as

$$
d\left[\mathrm{Y}_{i t} \cdot \exp (-r t)\right] / d t \leq 0
$$

The profitability and arbitrage conditions are pivotal for the subsequent process of technological diffusion in this model and determine two distinct aspects of the process. The profitability condition in (1) determines the set of potential adopters. The arbitrage condition contained in (3) determines the optimal adoption times, $t^{*}$, for each adopter. The optimal adoption date for institution $i, t_{i}^{*}$ will be given by the condition in (3). ${ }^{5}$

As shown by Karshenas and Stoneman (1993), the two adoption conditions can be translated into a relationship between the probability of adoption in the small time interval $(t, t+d t)$, i.e. the hazard rate, and the rank, stock, and order effects. The hazard rate is specified as

$$
h_{i t}=J\left[r_{t} P_{t}, K_{t}, C_{i}, p_{t}, k_{t} / r_{t}\right]
$$

\footnotetext{
${ }^{5}$ The inequality sign in (3) allows for the possibility of corner solutions. This could occur, for example, when the optimal date of adoption is the year of commercialisation. Karshenas and Stoneman (1993) provide a formal proof of the existence of an optimum value of (3) at some $t<\infty$.
} 
The function in (4) states that the conditional probability of adoption, $h_{i t}$, is a function of the interest saved, $r_{t} P_{t}$, stock effects, $K_{t}$, rank effects, $C_{i}$, the expected change in the price of technology, $p_{t}$, and the expected change in the number of users discounted by the interest rate, $k_{t} / r_{t}$. According to theoretical models of diffusion, the following first-order derivatives should apply: $J_{1}<0, J_{2}<0, J_{3} \geq 0, J_{4}>0, J_{5}>0$. Equation (4) forms the basis of estimation.

\section{THE DATA SET}

\subsection{The Set of Potential Adopters}

The enabling characteristic of an ATM is its ability to allow deposit-holding customers to access their accounts via a personal cash card (primarily to withdraw cash). The commercialisation of ATMs in the UK occurred in 1972 and this forms the start date of the empirical study. ${ }^{6}$ The adoption of ATMs in the UK has, unsurprisingly, been confined exclusively to two separate sectors within the financial sector: the retail banking sector and the building society sector.

In this paper the set of potential adopters is defined as the stock of retail banks and building societies at the end of 1997. The definition employed for retail banks is identical to that used by the Bank of England (1997) which focuses on two criteria. The first is that the institution must have a 'large' branch network in the UK. Secondly, the institution has to participate in the UK clearing system. At the end of 1997 there were 20 retail banks operating in the UK. The definition employed for building societies is purely an 'empirical' one and utilises the members of the Building Societies Association (BSA). At the end of 1997 there were a total of 86 members of the BSA (see BSA, 1997). These institutions were contacted and asked the year at which adoption (if any) of ATMs took place, adoption being defined as the year at which they first started to operate one or more ATMs. After excluding those institutions from which data was not forthcoming a total of 98 potential adopters were identified, of which 12 are retail banks and 86 are building societies. Following convention it was assumed that the number of adopters was constant throughout the period 1972 to 1997. As noted by Karshenas and Stoneman (1993) and Baptista (2000), sampling a stock of existing firms creates the potential for a selection bias since the sampling design explicitly

\footnotetext{
${ }^{6}$ First generation ATMs were first adopted in the UK in 1967 (Jones, 1981; Austin, 1992). These early machines did not, however, rely on a personal cash card in order to make withdrawals and did not directly debit the customers account. They therefore lay outside the definition used here.
} 
excludes those firms that exited the industry before the end of 1997. It was found that the probability of exit is uncorrected with the explanatory variables included. ${ }^{7}$

The stock of potential adopters includes 35 institutions that had not adopted on or before the end of 1997. These institutions are necessarily right-censored at 24 years as their spells of non-adoption were incomplete. For the period 1989 to 1997 the number of ATM adopters in this sample has remained identical. The fraction of ATM adopters overtime is shown in Figure 1 below.

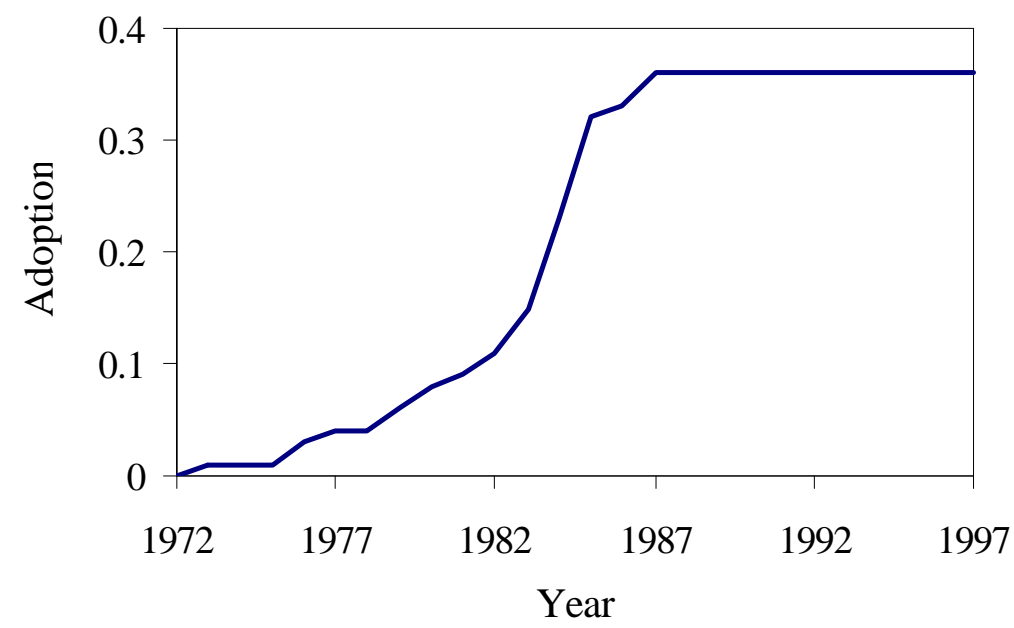

FIG. 1 Diffusion of ATMs

\subsection{Variables Affecting the Adoption Decision}

The covariates included in the rank effect have been subsumed in the vector $C_{i}$. The exact elements of this vector have, up to now, been left unspecified. A number of firm and industry-specific variables are deemed to influence the adoption decision.

Firm size plays a prominent role in rank models of diffusion (see Davies, 1979) and has traditionally been found to have a positive effect on the probability of adoption. Evidence provided by Humphrey (1994) suggests the existence of significant (positive) scale and scope economies for ATM technology. This suggests that adopting ATMs, ceteris paribus, is likely to be more profitable for relatively larger institutions.

As noted by Lawrence and Shay (1986), the deposits of financial institutions play a dual role in their production process. Their first role is to provide liquidity and transactions services. Secondly, deposits provide an input (together with capital and labour) in the production of other assets. During periods of rapid deposit growth, therefore, financial institutions may wish to expand capacity by adopting ATM technology.

\footnotetext{
${ }^{7}$ Full details of the estimated results can be obtained from the author.
} 
Scarborough and Lannon (1987), Ingham and Thompson (1993), and Haynes and Thompson (2000) have argued that the main characteristic of ATMs underlying their adoption has been the technology's inherent 'labour-saving' qualities. To measure the potential for labour-savings is extremely problematic. An ideal measure would be the capital-labour ratio defined over those capital and labour inputs employed directly in the provision of deposit services. In this paper the ratio of branch staff employed to branches operated is employed as a measure of the potential for labour-saving.

Empirical evidence provided by Hannan and McDowell $(1984,1987)$ suggests that after-tax retained profits are a significant factor affecting the timing of ATM adoption in the US banking sector. Consequently, liquidity constraints are measured as the ratio of after-tax profits to the value of assets (the latter being a measure of relative institution size).

The corporate status of a firm (either independent or part of a larger concern) may also have an impact on the decision to adopt. As noted by Rose and Joskow (1990), Karshenas and Stoneman (1993) and Baptista (2000), the effect of corporate status is likely to be ambiguous. On the one hand, independent institutions may be better positioned with regard to speed of implementation once the decision to adopt has been made. On the other, institutions that are part of a larger institution may be better informed and bear less risk in adopting new technology.

Church and Gandal (1993) and Colombo and Mosconi (1995) have found that the early adoption of previous vintage technologies may increase the marginal benefits from the adoption of later ones through learning-by-doing effects. In the case of ATM technology, first generation machines were first commercialised in 1967. As noted by Kirkman (1987), these were not strictly ATMs but, rather, cash dispensers. By the mid-1970s these machines had been phased-out (see British Bankers' Association, 1986). This potential of learning effects is captured by a dummy variable, taking a value of one if the institution has adopted first generation ATMs, and zero otherwise.

The potential influence of order effects is assessed by the number of firms expected to adopt in the following period. Assuming perfect foresight, this is measured as the first difference in the number of adopters at time $t$. Similarly, stock effects are measured as the accumulated number of adopters at time $t$. 


\section{ECONOMETRIC ESTIMATION}

A duration or failure time model (Kiefer, 1988; Heckman and Singer, 1984, 1985; Neumann, 1997) is employed to model the time to adoption as a function of the independent variables. The hazard rate is defined as the probability that firm $i$ will adopt the innovation at time $t$ conditional on the firm not having adopted the innovation before $t$. The main issue to address in modelling diffusion within this framework is how to incorporate the effect of firm-specific variables on this hazard rate. It was decided to choose a general class of models known as 'proportional hazard models' proposed by Cox (1972). These models have been employed extensively in previous diffusion studies (see Hannan and McDowell, 1987; Ingham and Thompson, 1993; Saloner and Shepard, 1995), and have the advantage of ensuring a positive hazard rate without the need to impose further restrictions on the parameters of the model. The general form of the proportional hazard function is

$$
h\left(t ; \mathrm{X}_{i t}, \beta\right)=h_{0}(t) \exp \left(\mathrm{X}_{i t} \beta\right)
$$

where $h_{0}(t)$ is the baseline hazard, $\mathrm{X}$ is a vector of explanatory variables incorporating the rank, stock, and order effects, and $\beta$ is a vector of parameters to be estimated. Estimation proceeds by maximum likelihood techniques (Kalbfleisch and Prentice, 1980; Neumann, 1997). Appendix B gives details of the likelihood function.

Estimation of the model in (5) can proceed by either estimating the baseline nonparametrically, or alternatively assuming a priori distribution. ${ }^{8}$ Two specifications of the baseline hazard, $h_{0}($.$) , were employed: the log-logistic and lognormal. The justification for$ employing these parametric functions is based on the nonparametric Kaplan-Meir (1958) estimate of the baseline hazard for ATM diffusion as shown in Figure 1 below. ${ }^{9}$ This suggests that the conditional probability of adoption increased up until 13 years postcommercialisation of ATMs and then decreased. For appropriate parameter values, both the log-logistic and lognormal distributions will display similar nonmonotonic properties (see Appendix B).

\footnotetext{
${ }^{8}$ Hannan and McDowell (1987) and Ingham and Thompson (1993) assume a constant baseline hazard in their empirical models.

${ }^{9}$ This nonparametric estimate is only defined up to the year at which the last adoption took place, and is then undefined for subsequent years. See Kalbfleisch and Prentice (1980) for details of this estimate.
} 


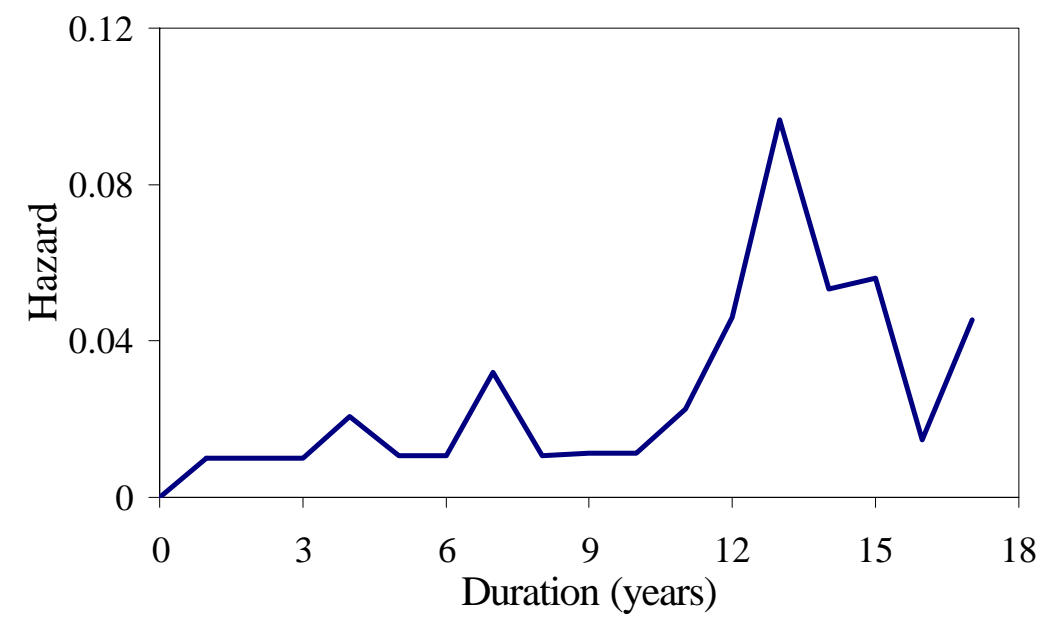

FIG 1. The Hazard Function

As noted by Karshenas and Stoneman (1993, 1995), however, it is not possible to identify seperately the baseline hazard from the epidemic hazard in (5). Following convention, epidemic effects are assumed to be absorbed into the baseline hazard. Epidemic effects are then tested by the time dependence of the baseline hazard. ${ }^{10}$

The Cox (1972) approach assumes that all covariates are exogenous. ${ }^{11}$ By definition this is the case for time-invariant covariates. For the set of the time-varying covariates, however, this assumption is likely to be violated by the inclusion of price variables and the stock of adopters at time $t, K_{t}$ (Karshenas and Stoneman, 1993). The real quality-adjusted price of ATMs fell throughout the sample period and this raises the question as to whether the price of technology is an endogenous variable and is the result of interaction between demand (i.e. the institutions) and supply (i.e. the ATM manufactures). The possible endogeneity of the first variable is, however, mitigated by the fact that a large proportion of ATM technology was imported during the early years of diffusion in the UK. The endogeneity of the former covariate is more of a concern because stock models assume that firm size is endogenous. This potential problem was tackled by employing a two-stage estimation procedure outlined by Lee (1981) and Murphy and Topel (1985). In the firststage a first-period time series autoregressive model is fitted for $K_{t}$. In the second stage,

\footnotetext{
${ }^{10}$ Heckman and Singer (1984, 1985) and Lancaster (1990) have argued that the baseline hazard will pick-up unobserved firm heterogeneity and will cause downward bias in the degree of duration dependence. Consequently, if estimates suggest positive duration dependence then this will provide empirical support for the importance of epidemic effects in the diffusion of ATMs.

${ }^{11}$ For a formal definition of exogeneity in duration models see Lancaster (1990).
} 
estimates of parameters from the first stage are employed to obtain estimates of $K_{t}$ and its first one-period ahead expectation, $k_{t}$.

\section{RESULTS}

Table 1 below summarises the definitions of all the variables used in estimation. Details of data sources are contained in Appendix C. Three specifications of the model contained in expression (4) were estimated, each employing a lognormal and a log-logistic baseline hazard. The first model estimated was the fully specified model that included all variables contained in Table 1. The second model imposes the restriction $\beta_{2}=0$. This allows the significance of stock effects to be tested using a likelihood ratio test. The third model to be estimated imposed the restriction $\beta_{4}=\beta_{5}=0$. This enables the significance of the order effects to be tested. The results obtained from these three models are contained in Tables 2 , 3 , and 4 respectively.

Table 1.

Definitions of Explanatory Variables

\begin{tabular}{|c|c|c|}
\hline Variable & & Description \\
\hline$p$ & $=$ & $\begin{array}{l}\text { Parameter of parametric models that determines duration } \\
\text { dependence }\end{array}$ \\
\hline CONSTANT & $=$ & Intercept term \\
\hline$S I Z E_{t}$ & $=$ & $\begin{array}{l}\text { Size of the institution, measured by the value of the total assets } \\
\text { deflated by the Producer Price Index (PPI) }\end{array}$ \\
\hline$G Y_{t}$ & $=$ & Growth in institutions deposits measured at time $t$ \\
\hline$r_{t}$ & $=$ & $\begin{array}{l}\text { Discount rate, measured by the yield on Treasury Bills expressed } \\
\text { as annual interest rates }\end{array}$ \\
\hline$k_{t}$ & $=$ & $\begin{array}{l}\text { Expected change in the cumulative number of adopters in the } \\
\text { interval }(t, t+1) \text { measured by }\left(K_{t+1}-K_{t}\right)\end{array}$ \\
\hline$K_{t}$ & $=$ & Cumulative number of adopters at time $t$ \\
\hline$p_{t}$ & $=$ & Expected change of the price of ATMs measured by $\left(P_{t+1}-P_{t}\right)$ \\
\hline$P_{t}$ & $=$ & Real price of ATMs (quality adjusted) at time $t$, deflated by PPI \\
\hline$S T A F F_{t}$ & $=$ & Total number of branch staff at time $t$ \\
\hline $\mathrm{BRANCH}_{t}$ & $=$ & Number of branches operated by each institution at time $t$ \\
\hline PROFITS $_{t}$ & & $\begin{array}{l}\text { Profitability of an institution, measured as the after-tax profits at } \\
\text { time } t\end{array}$ \\
\hline DPREVIOUS & & $\begin{array}{l}\text { A dummy variable taking the value of unity for previous cash } \\
\text { dispenser (1967 to 1971) adoption and zero otherwise }\end{array}$ \\
\hline$D S U B$ & & $\begin{array}{l}\text { A dummy variable taking the value of unity if the institution is a } \\
\text { subsidiary and zero otherwise }\end{array}$ \\
\hline
\end{tabular}


The dependent variable employed in all estimated models is the time to adoption. Consequently, a positive coefficient sign implies that the variable have a positive effect to the time to adoption, and conversely for a negative coefficient. From Table 2, the parameter vector $\beta$ remains relatively stable in terms of values and signs when comparing results from a lognormal specification of the baseline hazard to that of a log-logistic one. The loglikelihood ratio test for the existence of epidemic effects at the industry-wide level accepts the hypothesis of their existence. This is additionally a test of these two models against the exponential model specification, the latter of which imposes the condition $p=1$ (Cox and Oakes, 1984). Thus, acceptance of the existence of epidemic effects in the diffusion process is additionally a rejection of the exponential model specification.

The coefficient on $K_{t}$ (representing stock effects) though having the correct sign is found to be statistically insignificant. As noted by Karshenas and Stoneman (1993), this may not necessarily indicate the total absence of such effects and may alternatively be captured by the time-varying baseline hazard. If this is indeed the case then imposing the condition $\beta_{2}=0$ should lead to an increase in the estimated coefficient for $p$. As shown by Table 3 the reverse of this effect occurs and, moreover, the subsequent log-likelihood ratio test rejects the existence of stock effects.

Order effects are captured by the coefficient on $k_{t} / r_{t}$. The coefficient on this variable is statistically significant and has the correct sign a priori in both the fully specified model and restricted stock models. Moreover, the log-likelihood ratio-test for the existence of order effects in Table 4 rejects the absence of these effects at the 0.05 level.

Turning attention to the role of rank effects, it is apparent from Table 2 that these have played an extremely significant role in the diffusion of ATMs. The likelihood ratio-test for the joint significance of all the rank effects variables indicate that their existence cannot be rejected at the 0.001 level. In particular, the size of the institution, captured by SIZE ${ }_{t}$ has a positive and highly significant effect on the conditional probability of adoption. This is consistent with previous studies examining the diffusion of ATMs (see, for example, Ingham and Thompson, 1993).

The $S_{T A F F} /$ BRANCH$_{t}$ ratio although having the correct sign a priori is not found to be statistically significant in both the lognormal and log-logistic models. This result may reflect the fact that this variable is an inadequate proxy for the opportunity for labour saving associated with ATM technology. As noted by Kirkman (1987), the labour-saving potential for ATMs may have been overstated and those branch staff previously employed exclusively 
in the provision of demand services were simply re-deployed after the adoption of ATMs. Thus, this variable may be capturing the output mix of a financial institution rather than the potential for labour saving.

The positive and significant coefficients on PROFITS $_{t} /$ SIZE $_{t}$ and $G Y_{t}$ suggests that liquidity constraints have played an important role in the diffusion of ATMs. This is consistent with US evidence (Hannan and McDowell, 1987).

A notable aspect of the results is the role played by the learning-by-using variable, DPREVIOUS. This is found to have a positive and significant coefficient at the 0.001 level. This suggests that institutions with experience in using previous vintage ATM technology (which embodies similar characteristics to second generation technology) has a positive impact on the conditional probability of adoption. This supports the empirical evidence in Colombo and Mosconi (1995).

The coefficient on $D S U B$, although negative, is statistically insignificant. Thus, being a subsidiary institution does not have any significant impact on the conditional probability of adoption.

Another notable aspect of the results contained in Table 2 is the role of the technologyprice variable, $r_{t} P_{t}$ and that of the price expectations variable $p_{t}$. From Table 2 , the coefficient on $r_{t} P_{t}$ is of the correct sign as suggested by the theoretical literature, but is not found to be statistically significant. The coefficient on the price expectations variable, $p_{t}$, is found to be both of the correct sign and statistically significant. The significance of the price-expectations variable suggests that myopic-type models employed by Hannan and McDowell (1987) may be misspecified.

To investigate this issue in greater detail the model was estimated imposing the parameter restriction $\beta_{4}=\beta_{5}=0$. The results are shown in Table 4 and conform to the conventional specification of a myopic-type. In the context of the theoretical model outlined in Section 2, this parameter restriction implies that the optimal date of adoption is only governed by the profitability condition in expression (2). The results in Table 4 show that whilst the coefficient estimates of other variables remain relatively stable and of the same sign, the myopic model is rejected using the likelihood-ratio test to test the parameter restriction implied by the myopic model. 
Table 2.

Maximum Likelihood Estimates of Lognormal and Log-logistic Models

\begin{tabular}{|c|c|c|c|c|c|}
\hline \multirow{2}{*}{$\begin{array}{l}\text { Coefficient } \\
p\end{array}$} & \multirow{2}{*}{$\begin{array}{r}\text { Variable } \\
\text { TIME }\end{array}$} & \multicolumn{2}{|c|}{ Lognormal Model } & \multicolumn{2}{|c|}{ Log-logistic Model } \\
\hline & & 4.6085 & $(4.6090)^{* *}$ & 4.4262 & $(3.6318)^{* *}$ \\
\hline$\alpha_{1}$ & CONSTANT & 3.6275 & $(11.2490)^{* *}$ & 4.1000 & $(5.9110)^{* *}$ \\
\hline$\beta_{1}$ & $S I Z E_{t}$ & 0.0328 & $(3.6780)^{*}$ & 0.0319 & $(3.5650)^{* *}$ \\
\hline$\beta_{2}$ & $K_{t}$ & -0.0116 & $(1.8880)$ & -0.0085 & $(0.8000)$ \\
\hline$\beta_{3}$ & $G Y_{t}$ & 1.3137 & $(2.6710)^{*}$ & 1.8186 & $(1.9720)^{*}$ \\
\hline$\beta_{4}$ & $k_{t} / r_{t}$ & 0.9676 & $(2.5620)^{*}$ & 1.3714 & $(2.5669)^{* *}$ \\
\hline$\beta_{5}$ & $r_{t} P_{t}$ & 0.0249 & $(1.1750)$ & 0.0231 & $(1.2210)$ \\
\hline$\beta_{6}$ & $p_{t}$ & -0.0105 & $(2.0520)^{*}$ & -0.0076 & $(2.2780)^{*}$ \\
\hline$\beta_{7}$ & $S T A F F_{t} / B_{R A N C H}$ & 0.0118 & $(1.7270)$ & 0.0203 & $(1.8820)$ \\
\hline$\beta_{8}$ & PROFITS $_{t} /$ SIZE $_{t}$ & 8.9417 & $(2.0300)^{*}$ & 7.3210 & $(1.9550)^{*}$ \\
\hline$\beta_{9}$ & DPREVIOUS & 1.1116 & $(4.1490)^{* *}$ & 1.3094 & $(3.4260)^{* *}$ \\
\hline$\beta_{10}$ & $D S U B$ & -0.5876 & $(0.8600)$ & -0.4850 & $(0.8420)$ \\
\hline \multicolumn{2}{|c|}{ Median duration (years) } & 29.12 & $(5.97)^{* *}$ & 32.91 & $(4.32)^{* *}$ \\
\hline \multicolumn{2}{|c|}{ Log-likelihood } & -166.28 & & -166.22 & \\
\hline \multicolumn{2}{|c|}{ Number of observations } & 1749 & & 1749 & \\
\hline \multicolumn{2}{|c|}{ Number of individual institutions } & 98 & & 98 & \\
\hline \multicolumn{2}{|c|}{$\begin{array}{l}\text { Log-likelihood ratio test for the } \\
\text { existence of epidemic effects: } \\
(p=1)\end{array}$} & $14.28(\chi$ & $\left.{ }_{5}(1)=3.84\right)$ & 13.68 & $\left.{ }_{5}(1)=3.84\right)$ \\
\hline \multicolumn{2}{|c|}{$\begin{array}{l}\text { Log-likelihood ratio test for the } \\
\text { existence of order effects: } \\
\left(\beta_{4}=0\right)\end{array}$} & $29.02(\chi$ & $\left.{ }_{95}^{2}(1)=3.84\right)$ & 28.32 & $\left.{ }_{5}(1)=3.84\right)$ \\
\hline \multicolumn{6}{|c|}{$\begin{array}{l}\text { Log-likelihood ratio test for the } \\
\text { existence of rank effects: }\end{array}$} \\
\hline
\end{tabular}


Table 3.

Maximum Likelihood Estimates of Restricted Stock Lognormal and Log-logistic Models

\begin{tabular}{|c|c|c|c|c|}
\hline \multirow{2}{*}{$\begin{array}{l}\text { Coefficient } \\
p\end{array}$} & \multirow{2}{*}{$\begin{array}{l}\text { Variable } \\
\text { TIME }\end{array}$} & \multicolumn{2}{|c|}{ Lognormal Model } & Log-logistic Model \\
\hline & & 3.4210 & $(4.0128)^{* *}$ & $4.3119 \quad(3.9068)^{* *}$ \\
\hline$\alpha_{1}$ & CONSTANT & 4.2701 & $(9.2510)^{* *}$ & $4.4760 \quad(8.7090)^{* *}$ \\
\hline$\beta_{1}$ & $S I Z E_{t}$ & 0.0399 & $(2.2330)^{*}$ & $0.0394 \quad(2.3130)^{*}$ \\
\hline$\beta_{2}$ & $K_{t}$ & & - & - \\
\hline$\beta_{3}$ & $G Y_{t}$ & 1.1611 & $(2.3690)^{*}$ & $1.4845 \quad(2.5258)^{*}$ \\
\hline$\beta_{4}$ & $k_{t} / r_{t}$ & 1.2823 & $(2.3380)^{*}$ & $1.4165(2.1410)^{*}$ \\
\hline$\beta_{5}$ & $r_{t} P_{t}$ & 0.0339 & $(1.1470)$ & $0.0347 \quad(0.9590)$ \\
\hline$\beta_{6}$ & $p_{t}$ & -0.0041 & $(2.1430)^{*}$ & $-0.0067 \quad(2.2260)^{*}$ \\
\hline$\beta_{7}$ & $S T A F F_{t} / B_{R A N C H}$ & 0.0137 & $(1.9200)$ & $0.0193(1.9650)^{*}$ \\
\hline$\beta_{8}$ & PROFITS $_{t} /$ SIZE $_{t}$ & 12.8648 & $(2.1760)^{*}$ & $13.5720 \quad(2.0863)^{*}$ \\
\hline$\beta_{9}$ & DPREVIOUS & 0.6004 & $(1.9400)^{*}$ & $0.7110(1.9080)^{*}$ \\
\hline$\beta$ & $D S U B$ & -0.5056 & $(1.1010)$ & $-0.0413 \quad(1.4250)$ \\
\hline \multicolumn{2}{|c|}{ Median duration (years) } & 28.82 & $(4.25)^{* *}$ & $(4.17)^{* *}$ \\
\hline \multicolumn{2}{|c|}{ Log-likelihood } & -167.62 & & -167.16 \\
\hline \multicolumn{2}{|c|}{ Number of observations } & 1749 & & 1749 \\
\hline \multicolumn{2}{|c|}{ Number of individual institutions } & 98 & & 98 \\
\hline \multicolumn{2}{|c|}{$\begin{array}{l}\text { Log-likelihood ratio test for the } \\
\text { existence of epidemic effects: } \\
(p=1)\end{array}$} & \multicolumn{2}{|c|}{$16.16\left(\chi_{.95}^{2}(1)=3.84\right)$} & $15.08\left(\chi_{.95}^{2}(1)=3.84\right)$ \\
\hline \multicolumn{2}{|c|}{$\begin{array}{l}\text { Log-likelihood ratio test for the } \\
\text { existence of stock effects: } \\
\left(\beta_{2}=0\right)\end{array}$} & $2.68\left(\chi_{.9}^{2}\right.$ & 1) $=3.84)$ & $1.88\left(\chi_{.95}^{2}(1)=3.84\right)$ \\
\hline \multicolumn{2}{|c|}{$\begin{array}{l}\text { Log-likelihood ratio test for the } \\
\text { existence of rank effects: } \\
\left(\beta_{1}=\beta_{3}=\beta_{7}=\beta_{8}=\beta_{9}=\beta_{10}\right)\end{array}$} & \multicolumn{2}{|c|}{$60.14\left(\chi_{.95}^{2}(7)=12.60\right)$} & $54.46\left(\chi_{.95}^{2}(7)=12.60\right)$ \\
\hline
\end{tabular}


Table 4.

Maximum Likelihood Estimates of Restricted Myopic Lognormal and Log-logistic Models

\begin{tabular}{|c|c|c|c|c|c|}
\hline Coefficient & Variable & \multicolumn{2}{|c|}{ Lognormal Model } & \multicolumn{2}{|c|}{ Log-logistic Model } \\
\hline$p$ & $T I M E$ & 4.6478 & $(5.1406)^{* *}$ & 4.8556 & $(4.4272)^{* *}$ \\
\hline$\alpha_{1}$ & CONSTANT & 3.1867 & $(12.4200)^{* *}$ & 3.2712 & $(10.6100)^{* *}$ \\
\hline$\beta_{1}$ & $S I Z E_{t}$ & 0.0035 & $(2.3130)^{*}$ & 0.0039 & $(2.3130)^{*}$ \\
\hline$\beta_{2}$ & $K_{t}$ & -0.0133 & $(1.6420)$ & -0.0111 & $(1.7360)$ \\
\hline$\beta_{3}$ & $G Y_{t}$ & 1.0346 & $(2.4870)^{*}$ & 1.2413 & $(2.0710)^{*}$ \\
\hline$\beta_{4}$ & $k_{t} / r_{t}$ & & - & & - \\
\hline$\beta_{5}$ & $r_{t} P_{t}$ & 0.0121 & $(0.7750)$ & 0.0062 & $(0.8286)$ \\
\hline$\beta_{6}$ & $p_{t}$ & & - & & - \\
\hline$\beta_{7}$ & $\mathrm{STAFF}_{t} / \mathrm{BRANCH}_{t}$ & 0.0110 & $(1.9620)^{*}$ & 0.0156 & $(1.6970)$ \\
\hline$\beta_{8}$ & $\mathrm{PROFITS}_{t} / \mathrm{SIZE}_{t}$ & 13.9857 & $(2.3920)^{*}$ & 13.4102 & $(2.0270)^{*}$ \\
\hline$\beta_{9}$ & DPREVIOUS & 0.9140 & $(4.7040)^{* *}$ & 1.0351 & $(4.0410)^{* *}$ \\
\hline$\beta_{10}$ & $D S U B$ & -0.2086 & $(0.8660)$ & -0.4203 & $(0.8840)$ \\
\hline \multicolumn{2}{|c|}{ Median duration (years) } & 28.82 & $(10.96)^{* *}$ & 24.36 & $(9.86)^{* *}$ \\
\hline \multicolumn{2}{|c|}{ Log-likelihood } & -173.56 & & -175.58 & \\
\hline \multicolumn{2}{|c|}{$\begin{array}{l}\text { Number of observations } \\
\text { Number of individual institutions }\end{array}$} & 1749 & & 1749 & \\
\hline Number of & ndividual institutions & 98 & & 98 & \\
\hline
\end{tabular}

Log-likelihood ratio test for the existence of epidemic effects: $(p=1)$

$21.64\left(\chi_{.95}^{2}(1)=3.84\right) \quad 23.60\left(\chi_{.95}^{2}(1)=3.84\right)$

Log-likelihood ratio test for the existence of expectation effects: $\left(\beta_{4}=\beta_{6}=0\right)$ $14.56\left(\chi_{.95}^{2}(1)=3.84\right) \quad 18.72\left(\chi_{.95}^{2}(1)=3.84\right)$

Log-likelihood ratio test for the existence of rank effects:
$\left(\beta_{1}=\beta_{3}=\beta_{7}=\beta_{8}=\beta_{9}=\beta_{10}\right)$
$47.40\left(\chi_{.95}^{2}(7)=12.60\right)$
$49.00\left(\chi_{.95}^{2}(7)=12.60\right)$

Notes: ** Significant at 1 per cent.

* Significant at 5 per cent.

$t$ statistics in parentheses. 


\section{CONCLUSION}

The empirical contribution of this paper has been to estimate a number of duration models for a panel data set of adoption histories in the UK financial sector. The methodology allowed for the explicit incorporation of time and time-varying covariates.

The empirical results indicate that rank effects have played an extremely significant role in the diffusion of ATMs, thus supporting probit-type theoretical models. Institution size, growth in deposits and profitability were all found to have a positive and significant effect on the conditional probability of adoption. Moreover, the results suggest that early adoption of previous vintage technologies (resulting in learning-by-doing effects) play a significant role in fostering faster diffusion. Consequently, the former technology history of the firm affects current adoption decisions. No significant role was found, however, for the labour-saving potential of ATMs. Reassuringly, the results were found to be robust across different specifications of the baseline hazard.

There was no support given to the existence of stock effects, although order effects entered the empirical model with the correct sign and was found to be statistically significant.

The empirical results lend support to the existence of epidemic effects in the diffusion of ATMs and it was illustrated that this was not due to the potential problem of distinguishing between stock effects and the time-varying nature of the baseline hazard. Moreover, the potential problem of differentiating between time-dependence and durationdependence as outlined by Colombo and Mosconi (1995) was shown not to apply to the set of ATM adopters and, thus, strengthens this result.

It was further found that expectations formed on the number of adopters and the price of technology have a significant role to play in the diffusion process, although the real quality-adjusted price of technology fails to register a significant effect. This lends further support to the work of Karshenas and Stoneman (1993) that models specifying myopic expectations may be seriously mis-specified.

In terms of fulfilling the second objective of the paper, the results appear to be robust across different specifications of the baseline hazard. This is consistent with previous diffusion studies. The decision of whether or not to impose a structure on the baseline hazard does not appear to radically alter estimates and inferences. 


\section{APPENDIX A. DERIVATION OF THE LIKELIHOOD FUNCTION}

As shown by Karshenas and Stoneman (1993, 1995) and Mosconi and Colombo (1995), the log-likelihood function can be derived from theoretical model outlined in Section 2. This is be achieved by introducing a stochastic element into the model. The arbitrage condition in (3) is transformed into the following condition

$$
y_{i t}+\varepsilon \leq 0
$$

where $\varepsilon$ is a stochastic error term whose distribution remains invariant across firms and overtime. Writing the arbitrage condition in (3) as $y_{i t}$, and assuming $\varepsilon$ is distributed independently of $y_{i}$ with a distribution function $\Psi(\varepsilon)$, the hazard rate has the form (Cox, 1972; Kalbfleisch and Prentice, 1980)

$$
h_{i t}=\operatorname{Pr}\left[y_{i t}+\varepsilon \leq 0\right]=\Psi\left[-y_{i t}\right]
$$

where $\Psi(\varepsilon)$ is the distribution function of the stochastic error term.

The unconditional probability of adoption can be represented as a function $f($.) of time and the variables influencing adoption, plus a set of parameters. If $f($.$) defines the density$ function for adoption times, then

$$
f=f\left(t ; \mathrm{X}_{i t} \beta\right)
$$

The joint density function for adoption times is then used to set up a likelihood function. Since the observations for some firms may be right-censored in the sense that not all firms have adopted on or before the end of the censoring time, the likelihood function $L(\beta)$ is

$$
L(\beta)=\Pi_{1}^{n}\left\{f\left(t ; \mathrm{X}_{i t} \beta\right)^{\theta} \cdot\left[1-F\left(t ; \mathrm{X}_{i t} \beta\right)^{(1-\theta)}\right]\right\}
$$

where $F($.$) is the distribution function corresponding to f($.$) and \theta$ is an indicator variable that takes the value of unity for firms who have adopted by the censoring time and zero for right-censored firms. 


\section{APPENDIX B. SPECIFICATION OF THE BASELINE HAZARD}

The lognormal hazard function has the following specification

$$
h(t)=\frac{(p / t) \phi\{[p \ln (\lambda t)]\}}{\Phi[-p \ln (\lambda t)]}
$$

where $\phi($.$) is the probability density function (PDF) and \Phi($.$) is the cumulative density$ function $(\mathrm{CDF})$. The lognormal hazard imposes the restriction $p>0$. It increases monotonically from $t=0$, obtains a maximum value determined by the value of $p$ and then approaches 0 as $t$ approaches infinity. The higher value of $p$, ceteris paribus, the higher the maximum value of the hazard.

The log-logistic hazard has the following specification

$$
h(t)=\frac{\lambda p(\lambda t)^{p-1}}{1+(\lambda t)^{p}}
$$

The log-logistic hazard is decreasing from infinity for $\forall t$ if $p=1$; increases from 0 to a maximum at $t=(p-1)^{1 / p} / \lambda$ and decreases toward 0 thereafter if $p>1$.

\section{APPENDIX C. DATA SOURCES}

- The yield on Treasury Bills was obtained from Table $7.1 \mathrm{H}$ of various copies of Financial Statistics, Office for National Statistics (ONS), Stationary Office, London.

- Producer Price Index (PPI) was obtained from Table 2.1 of various copies of Economic Trends, ONS, Stationary Office, London.

- Quality adjusted price of ATMs was supplied by the ONS, Cardiff. 
- Data on retail banks and building societies were obtained from previous editions of the Annual Abstract of Banking Statistics, British Bankers' Association, London and the Building Societies Yearbook, Building Societies Association, London and from direct correspondence with the institutions themselves.

- Data on the time of adoption of ATMs for both retail banks and building societies were obtained from direct correspondence with the relevant institutions.

\section{REFERENCES}

Austin, D. (1992). 'Needles and PINs', Banking Technology, November, pp. 59-63.

Bank of England (1986). 'The UK approach to financial regulation, Bank of England Quarterly Bulletin, Vol. 26, London.

Bank of England (1997). Statistical Abstract, Bank of England, London.

Baptista, R. (2000). 'Do innovations diffuse faster within geographical clusters?', International Journal of Industrial Organisation, Vol. 18, pp. 515-535.

British Bankers' Association (1996). Annual Abstract of Banking Statistics, London.

Building Societies Association (1997). Building Societies Yearbook 1996-1997, London.

Church, J. and Gandal, N. (1993). 'Complementary network externalities and technological adoption', International Journal of Industrial Organisation, Vol. 11, pp. 239-260.

Colombo, M. G. and Mosconi, R. (1995). 'Complementary and cumulative learning effects in the early diffusion of multiple technologies', Journal of Industrial Economics, Vol. 43, pp. 13-48.

Cox, D. R. (1972). 'Regression models and life-tables', Journal of the Royal Statistical Society, Vol. 34, pp. 187-220.

Cox, D. R. and Oakes, D. (1984). Analysis of Survival Data, New York, Chapman and Hall.

Davies, S. (1979) The Diffusion of Process Innovations, Cambridge, Cambridge University Press.

Fudenberg, D. and Tirole, J. (1985). 'Preemption and rent equalization in the adoption of new technology', Review of Economic Studies, Vol. 52, pp. 383-401.

Geroski, P. A. (2000). 'Models of technology diffusion', Forthcoming, Research Policy.

Griliches, Z. (1957). 'Hybrid corn: an exploration in the economics of technological change', Econometrica, Vol. 25, pp. 501-522. 
Hannan, T. H. and McDowell, J. M. (1984). 'The determinants of technology adoption: the case of the banking firm', Rand Journal of Economics, Vol. 15, pp. 328-335.

Hannan, T. H. and McDowell, J. M. (1987). 'Rival precedence and the dynamics of technology adoption: an empirical analysis', Economica, Vol. 54, pp. 155-171.

Haynes, M. and Thompson, S. (2000). 'Productivity, employment and the "IT Paradox": evidence from financial services', Forthcoming, Oxford Economic Papers.

Heckman, J. J. and Singer, B. (1984). 'Econometric duration analysis', Journal of Econometrics, Vol. 24, pp. 63-132.

Heckman, J. J. and Singer, B. (1985). 'Social science and duration analysis', in , J. J. Heckman and B. Singer (editors), Longitudinal Analysis of Labour Market Data, Cambridge University Press, Cambridge.

Humphrey, D. B. (1994). 'Delivering deposit services: ATMs versus branches', Federal Reserve Bank of Richmond Quarterly, Vol. 80, pp. 59-81.

Ingham, H. and Thompson, S. (1993). 'The adoption of new technology in financial services: the case of building societies', Economics of Innovation and New Technology, Vol. 2, pp. 263-274.

Ireland, N. J. and Stonemam, P. (1985). 'Order effects, perfect foresight and intertemporal price discrimination', Recherches Economiques de Louvain, Vol. 51, pp. 7-20.

Ireland, N. J. and Stoneman, P. (1986). 'Technological diffusion, expectations and welfare', Oxford Economic Papers, Vol. 38, pp. 283-304.

Jones, D. (1981). 'ATMs invade the high street', The Bankers' Magazine, November, pp. 2932.

Kalbfleisch, J. D. and Prentice, R. L. (1980). The Statistical Analysis of Failure Time Data, John Wiley, New York.

Kalbfleisch, J. D. and R. L. Prentice (1980). The Statistical Analysis of Failure Time Data, New York, John Wiley.

Kamien, M. L. and Schwartz, N. L. (1982). Market Structure and Innovation, Cambridge University Press, Cambridge.

Kaplan, E. L. and Meier, P. (1958). 'Nonparametric estimation from incomplete observations', Journal of American Statistical Association, Vol. 53, pp. 457-481.

Karshenas, M. and Stoneman, P. (1993). 'Rank, stock, order, and epidemic effects in the diffusion of new process technologies: an empirical model', Rand Journal of Economics, Vol. 24, pp. 503-528. 
Karshenas, M. and Stoneman, P. (1995). 'Technological Diffusion', in P. Stoneman (editor) Handbook of the Economics of Innovation and Technological Change, Oxford, Blackwell.

Kiefer, N. M (1988). 'Economic Duration data and hazard functions', Journal of Economic Literature, Vol. 26, pp. 646-679.

Kirkman, P. (1987). Electronic Funds Transfer Systems: The Revolution in Cashless Banking and Payments Methods, London, Basil Blackwell.

Lancaster, L. (1990). The Econometric Analysis of Transition Data, Cambridge University Press, Cambridge.

Lawless, J. F. (1982). Statistical Methods for Lifetime Data, New York, John Wiley.

Lawrence, C. and Shay, R. P. (1986). 'Technology and financial intermediation in multiproduct banking firms: an econometric study of US banks, 1979-1982', in C. Lawrence and R. P. Shay (editors), Technological Innovation, Regulation, and the Monetary Economy, Massachusetts, Ballinger, Cambridge.

Lee, L. F. (1981). 'Simultaneous equation models with discrete and censored variables', in C. F. Manski and D. McFadden (editors), Structural Analysis of Discrete Data with Econometric Applications, MIT Press, Cambridge, Massachusetts.

Lissoni, F. and Metcalfe, J. S. (1994). 'Diffusion of Innovation Ancient and Modern: A Review of the Main Themes', in M. Dodgson and R. Rothwell (editors), The Handbook of Industrial Innovation, Aldershot, Edward Elgar.

Llewellyn, D. T. (1992). 'Financial Innovation: A Basic Analysis', in H. Cavana (editor), Financial Innovation, London, Routledge.

Llewellyn, D. T. (1997). 'Technology transforms the banking industry', Financial Technology Review, pp. 1-4, Euromoney Publications, Colchester.

Mansfield, E. (1968). The Economics of Technical Change, New York, Norton.

Matutes, C. and Padilla, A. J. (1994). 'Shared ATM networks and banking competition', European Economic Review, Vol. 38, pp. 1113-1138.

Murphy, K. M. and Topel, R. H. (1985). 'Estimation and inference in two-step econometric models', Journal of Business and Economic Statistics, Vol. 3, pp. 370-379.

Neumann, G. R. (1997). 'Search models and duration data', in M. H. Pesaran and P. Schmidt (editors), Handbook of Econometrics: Microeconomics, Blackwell, Oxford.

Pawley, M. (1993). Financial Innovation and Monetary Policy, Routledge, London. 
Petersen, T. (1986a). 'Estimating fully parametric hazard rate models with time-dependent covariates: use of maximum likelihood', Sociological Methods and Research, Vol. 14, pp. 219-246.

Petersen, T. (1986b). 'Fitting parametric survival models with time-dependent covariates', Applied Statistics, Vol. 35, pp. 281-288.

Podolski, T. M. (1986). Financial Innovation and the Money Supply, Oxford, Basil Blackwell.

Quirmbach, H. C. (1986). 'The diffusion of new technology and the market for an innovation', Rand Journal of Economics, Vol. 17, pp. 33-47.

Reinganum, J. F. (1981a). 'On the diffusion of new technology: a game theoretic approach', Review of Economic Studies, Vol. 48, pp. 395-405.

Reinganum, J. F. (1981b). 'Market structure and the diffusion of new technology', The Bell Journal of Economics, Vol. 12, pp. 618-624.

Reinganum, J. F. (1989). ‘The theory of innovation: research, development and diffusion', in R. Schmalensee and R. D. Willig (editors), Handbook of Industrial Organisation, NorthHolland, Amsterdam.

Rose, N. L. and Joskow, P. L. (1990). 'The diffusion of new technologies: evidence from the electric utility industry', Rand Journal of Economics, Vol. 21, pp. 354-373.

Saloner, G. and Shepard, A. (1995) 'Adoption of technologies with network effects: an empirical examination of the adoption of automated teller machines', Rand Journal of Economics, Vol. 26, pp. 479-501.

Sarkar, J. (1998). 'Technological diffusion: alternative theories and historical evidence', Journal of Economic Surveys, Vol. 12, pp. 131-176.

Scarborough, H. and Lannon, R. (1988). 'The successful exploitation of new technology in banking', Journal of General Management, Vol. 13, pp. 38-51.

Sinha, R. K. and Chandrashekaran (1992), M. 'A split hazard model for analysing the diffusion of innovations', Journal of Marketing, Vol. 29, pp. 116-127 